\title{
A DYNAMICAL SYSTEM APPROACH IN MODELING TECHNOLOGY TRANSFER
}

\author{
Hennie Husniah $^{1}$, Sebrina ${ }^{2}$ And A.K. Supriatna ${ }^{3}$ \\ ${ }^{1}$ Department of Industrial Engineering, Langlangbuana University, \\ Bandung 40261, Indonesia \\ email: hennie.husniah@gmail.com \\ ${ }^{2}$ PT Chevron Pacific Indonesia Rumbai, Pekanbaru, \\ Riau 28271, Indonesia \\ email: sebrinafrey@gmail.com \\ ${ }^{3}$ Department of Mathematics, Padjadjaran University, \\ Jatinangor 45363, Indonesia \\ email: a.k.supriatna@unpad.ac.id
}

\begin{abstract}
In this paper we discuss a mathematical model of two parties technology transfer from a leader to a follower. The model is reconstructed via dynamical system approach from a known standard Raz and Assa model and we found some important conclusion which have not been discussed in the original model. The model assumes that in the absence of technology transfer from a leader to a follower, both the leader and the follower have a capability to grow independently with a known upper limit of the development. We obtain a rich mathematical structure of the steady state solution of the model. We discuss a special situation in which the upper limit of the technological development of the follower is higher than that of the leader, but the leader has started earlier than the follower in implementing the technology. In this case we show a paradox stating that the follower is unable to reach its original upper limit of the technological development could appear whenever the transfer rate is sufficiently high. We propose a new 'paradox-free' model to increase realism so that any technological transfer rate could only has a positive effect in accelerating the rate of growth of the follower in reaching its original upper limit of the development.
\end{abstract}

Key words and Phrases: Dynamical system, technology transfer, knowledge management, logistic curve.

2000 Mathematics Subject Classification: 90B70, 37N40, 97M50. Received: 04-07-2015, revised: 23-03-2016, accepted: 26-03-2016. 


\begin{abstract}
Abstrak. Di dalam makalah ini dibahas sebuah model matematika mengenai transfer teknologi dari seorang individu atau suatu parti yang disebut leader kepada seorang individu atau suatu parti yang disebut follower. Model tersebut direkonstruksi melalui pendekatan sistem dinamik dari model standar Raz-Assa yang sudah dikenal. Hasil analisis model memperlihatkan sebuah sifat dari model hasil rekonstruksi yang tidak ada dalam bahasan model aslinya. Model Raz-Assa mengasumsikan bahwa ketika tidak ada transfer teknologi, masing-masing individu atau parti mempunyai kapasitas untuk berkembang secara independen menuju batas atas yang diketahui. Selain itu juga diperlihatkan sifat-sifat solusi setimbang dari model tersebut di atas. Kemudian juga dibahas situasi khusus di mana follower mempunyai batas atas perkembangan yang lebih tinggi dibandingkan dengan leader, namun terlambat dalam implementasi teknologi terkait dibandingkan dengan leader tersebut. Dalam situasi seperti ini akan diperlihatkan suatu paradox di mana follower tidak akan pernah mencapai batas atas kapasitasnya apabila laju transfer teknologi terlalu tinggi. Untuk mengatasi paradox ini sebuah model baru diperkenalkan, sehingga laju transfer teknologi selalu memberikan efek positif terhadap follower dalam hal pencapaian batas atas pengembangan teknologinya.
\end{abstract}

Kata kunci: Sistem dinamik, Transfer Teknologi, Manajemen Ilmu, Kurva Logistik

\title{
1. INTRODUCTION
}

Technology transfer has been defined as a process of the implementation of scientific/technological information developed in one area into another area, or equivalently defined as a process of migration and redeployment of technology from one area into different area $[2,18,22]$. The transfer could be done either by a market oriented mechanism, e.g. purchasing, licensing, etc., or a non market oriented mechanism, e.g. academic journal, industrial fair, etc. [16]. Three main components in the process of technology transfer are the technology, the owner of the technology (also called as a leader, transferor, or donor), and the recepient (also called as a follower, transferee, or receiver). The process is usually complex involving many related aspects, such as the properties of the technology being transfered, the transferor capability of tranferring, and the transferee capability of adapting the technology $[4,14]$.

One important thing of technology transfer is the assesment of the future and the long-term behaviour of the technology transfer, which is known as technological forecasting [26]. There are many literatures discussing this important, yet complicated, area of research. In general, mathematical modeling has been widely accepted as one approach in attacking complicated problems in many areas of industrial engineering research (e.g. [6, 7, 9, 8, 1, 17]). However, despite numerous works on technology transfer, to date the use of mathematical modeling in this area is still limited. Among the known literatures on technology transfer that utilize mathematical models are $[5,10,15,19,20,23]$. These models, and also related models regarding technological diffusion, e.g. [21], have been critically reviewed in [16].

In two closely related papers $[19,20]$, the hypothesis that the rate of growth of a transferee is proportional to the indigenous development of the transferee, the 
technology gap between the transferor and the transferee, and the function governing the technology transfer rate are used to develop the model for investigating technology transfer which relates to the behaviours of the technological leader and followers. In general, the model of the technological follower consists of two contributions, those from indigenous development indicating by the indigenous ability to develop $\left(k_{F}\right)$ and those from the interaction between the technology transfer rate $\left(k_{T}\right)$ and the technology gap between the leader and the follower. The general form of the model is given by

$$
\frac{d X_{F}(t)}{d t}=k_{F} f_{0}\left(X_{F}(t)\right)+k_{T} f_{1}\left(X_{F}(t)\right) f_{2}\left(X_{F}(t), X_{L}(t)\right)
$$

Here $X_{F}(t)$ is a measure of technological development for the follower and usually in the form of logistic growth (it is also called sigmoid, S-type growth, a growth with saturation [13]), or Gompertz-type growth [24].

In this paper we reconstruct and paraphrasing the model in [19], which is a special form of equation (1), via dynamical system approach [25]. This approach is similar to system dynamics approach proposed by Jay Forrester [3] and among the best framework available in predicting the long-term behaviour of the solution of dynamic systems, such the case in technology transfer. Recently, system dynamic approach has been used in addressing technological forecasting problems, since it can enhance insight in the essence of the problems by allowing the development of more complex model to investigate the structures and to further focus on the processes of the underlying technological forecasting aspect [11].

We found some important hidden notions of technological transfer arising from the model of Raz and Assa [19], which have not been discussed in their original paper. For example, we show a paradox stating that 'the follower is unable to reach its original upper limit of the technological development could appear whenever the transfer rate is sufficiently high'. This is caused by an implicit assumption that there might be a negative effect of technology transfer whenever the transferee has a significant ability to develop in the absence of technology transfer. We propose a new model of technology transfer by modifying those in [19], which appropriately fits to reflect a technology transfer in which the transferee has a significant ability to develop in the absence of technology transfer. In this new model we assume that the presence of technology transfer from the transferor always has a positive effect in the technology development of the transferee. The model has a wide spectrum of application as long as we provide appropriate measurement to the level of development of the technology under consideration.

\section{Raz and Assa Coupled Logistic Model}

In this section we discuss the model of coupled technology transfer developed by Raz and Assa [19]. In the absence of technology transfer they assume that both the leader and the follower have a logistic curve $X_{L}(t)$ and $X_{F}(t)$, respectively, to describe the growth of their technological development. The logistic equation for 
the leader is given by

$$
X_{L}(t)=\frac{u_{L}}{1+b_{L} e^{-K_{L} t}},
$$

and for the follower is given by

$$
X_{F}(t)=\frac{u_{F}}{1+b_{F} e^{-K_{F} t}}
$$

where $b_{L}$ and $b_{F}$ are constants and:

$u_{L}$ - is the upper limit of the technological development of the leader,

$u_{F}$ - is the upper limit of the technological development of the follower,

$k_{L}$ - is the indigenous ability of the leader to develop,

$k_{F}$ - is the indigenous ability of the follower to develop.

In this model, without any technology transfer from the leader, equation (3) tells us that the follower could attain the maximum level of the technology development by solely use of its indigenous ability to develop. In the presence of technology transfer, their model (equations (5) and (10) in [19]) takes the form

$$
\begin{gathered}
X_{L}(t)=\frac{u_{L}}{1+b_{L} e^{-K_{L} t}}, \\
\frac{d X_{F}(t)}{d t}=g_{F}+K_{T}\left(X_{L}(t)-X_{F}(t)\right),
\end{gathered}
$$

where $g_{F}=b_{F} K_{F} e^{K_{F} t} U_{F}\left(1+b_{F} e^{-K_{F} t}\right)^{-2}$. It is easy to check that the right hand side of equation (4) is the solution of the logistic differential equation

$$
\frac{d X_{L}(t)}{d t}=k_{L} X_{L}(t)\left(1-\frac{X_{L}(t)}{u_{L}}\right)
$$

with $b=u_{L}-X_{L}(0)$, where $X_{L}(0)$ is the initial condition of the leader development at $t=0$. Consequently, equation (4) can be replaced by equation (6). Note also that $g_{F}$ in equation (5) is actually the growth rate of the follower development in the absence of technology transfer, that is $g_{F}=\frac{d}{d t}\left(\frac{u_{F}}{1+b_{F} e^{-K_{F}}}\right)=\frac{d \tilde{X}_{F}(t)}{d t}$. Using a similar argument as in the case of the leader, $g_{F}$ in equation (5) can also be replaced by $\frac{d \tilde{X}_{F}(t)}{d t}=k_{F} X_{F}(t)\left(1-\frac{X_{F}(t)}{u_{F}}\right)$. Hence, the system (4-5) can be rewritten in the form

$$
\begin{gathered}
\frac{d X_{L}(t)}{d t}=k_{L} X_{L}(t)\left(1-\frac{X_{L}(t)}{u_{L}}\right) \\
\frac{d X_{F}(t)}{d t}=k_{F} X_{F}(t)\left(1-\frac{X_{F}(t)}{u_{F}}\right)+k_{T}\left(X_{L}(t)-X_{F}(t)\right) .
\end{gathered}
$$

Raz and Assa [19] solved the system (4-5) numerically and studied the behaviour of the solution by varying the parameters in the model. In this paper we reconstruct their finding by investigating the alternative system, i.e. equations (7-8) via dynamical system approach to study the long-term behaviour of the system. The following propositions are the results derived by investigating the critical points of the systems via linearization method (see [12] : p. 168 for an introductory). 
Proposition 2.1. The system of equations (7) and (8) has four steady state solutions with exactly one positive steady state solution.

Proof. The steady state solutions of equations (7) and (8) are obtained by equating both equations to zero and solve for $X_{L}$ and $X_{F}$. The system has four steady states, namely $\left(X_{L 0}^{*}, X_{F 0}^{*}\right)=(0,0),\left(X_{L 1}^{*}, X_{F 1}^{*}\right)=\left(0, \frac{u_{F}\left(k_{F}-k_{T}\right)}{k_{F}}\right),\left(X_{L 2}^{*}, X_{F 2}^{*}\right)=$ $\left(u_{L}, Z_{1}^{*}\right),\left(X_{L 3}^{*}, X_{F 3}^{*}\right)=\left(u_{L}, Z_{2}^{*}\right)$, where $Z_{1}^{*}$ and $Z_{2}^{*}$ are the roots of the quadratic equation $k_{F} Z^{2}+\left(k_{T}-k_{F}\right) u_{F} Z-k_{T} u_{F} u_{L}$, which is given by $X_{F 2}^{*}=\frac{u_{F}\left(k_{F}-k_{T}\right)+D}{2 k_{F}}$ and $X_{F 3}^{*}=\frac{u_{F}\left(k_{F}-k_{T}\right)-D}{2 k_{F}}$, where $D=\sqrt{\left(u_{F}\left(k_{T}-k_{F}\right)\right)^{2}+4 k_{F} k_{T} u_{F} u_{L}}$. The expression in $X_{F 2}^{*}$ and $X_{F 3}^{*}$ ensure that there is a non-trivial steady state. Furthermore, since the product of the roots is negative then there is exactly one positive non-trivial steady state.

The proof in the proposition shows that the indigenous ability of the leader to develop $\left(k_{L}\right)$ does not appear in the steady state. This means that the level of the technological development of the follower is independent from the indigenous ability of the leader to develop. However, the upper limit of the technological development of the leader $\left(u_{L}\right)$ and the rate of technology transfer $\left(k_{T}\right)$ critically affect the technological development of the follower with the structural properties described in Propositions 2.1 to 2.4.

Proposition 2.2. The positive steady state solution $\left(X_{L 2}^{*}, X_{F 2}^{*}\right)=\left(u_{L}, Z_{1}^{*}\right)$ is stable while all other steady states are unstable.

Proof. The stability of a steady state is determined by the negative sign of all the eigenvalues of the associated Jacobian matrix.

(1) The eigen values of the Jacobian matrix for $\left(X_{L 0}^{*}, X_{F 0}^{*}\right)$ are $k_{L}$ and $k_{F}-k_{T}$, which is not all negative.

(2) The eigen values of the Jacobian matrix for $\left(X_{L 1}^{*}, X_{F 1}^{*}\right)$ are $k_{L}$ and $k_{T}-k_{F}$, which is not all negative.

(3) The eigen values of the Jacobian matrix for $\left(X_{L 2}^{*}, X_{F 2}^{*}\right)$ are $-k_{L}$ and $-\frac{\sqrt{k_{F}^{2} u_{F}^{2}-2 k_{F} u_{F}^{2} k_{T}+k_{T}^{2} u_{F}^{2}+4 k_{F} k_{T} u_{F} u_{L}}}{u_{F}}=-\frac{\sqrt{\left(u_{F}\left(k_{T}-k_{F}\right)\right)^{2}+4 k_{F} k_{T} u_{F} u_{L}}}{u_{F}}$, which is all negative.

(4) The eigen values of the Jacobian matrix for $\left(X_{L 3}^{*}, X_{F 3}^{*}\right)$ are $-k_{L}$ and $-\frac{\sqrt{k_{F}^{2} u_{F}^{2}-2 k_{F} u_{F}^{2} k_{T}+k_{T}^{2} u_{F}^{2}+4 k_{F} k_{T} u_{F} u_{L}}}{u_{F}}=\frac{\sqrt{\left(u_{F}\left(k_{T}-k_{F}\right)\right)^{2}+4 k_{F} k_{T} u_{F} u_{L}}}{u_{F}}$, which is not all negative.

Proposition 2.3. The stable steady state solution $\left(X_{L 2}^{*}, X_{F 2}^{*}\right)$ has the following properties:

(1) If $u_{F}>u_{L}$ then 
(a) in general $u_{F} \frac{k_{F}-k_{T}}{k_{F}}<X_{F 2}^{*}<u_{F}$,

(b) if furthermore $k_{F}>k_{T}$ then $u_{L}<X_{F 2}^{*}<u_{F}$.

(2) If $u_{F}<u_{L}$ then

(a) in general $u_{F}<X_{F 2}^{*}<u_{L} \frac{k_{F}+k_{T}}{k_{F}}$,

(b) if furthermore $k_{F}>k_{T}$ then $u_{F}<X_{F 2}^{*}<u_{L}$.

(3) If $u_{F}=u_{L}$ then $X_{F 2}^{*}=u_{L}$.

ProOF.

(1) Case $u_{F}>u_{L}$.

(a) First we prove the left part of the inequality in the general case,

$$
\begin{aligned}
X_{F 2}^{*} & =\frac{u_{F}\left(k_{F}-k_{T}\right)+\sqrt{\left(u_{F}\left(k_{F}-k_{T}\right)\right)^{2}+4 k_{F} k_{T} u_{F} u_{L}}}{2 k_{F}} \\
& >\frac{u_{F}\left(k_{F}-k_{T}\right)+\sqrt{\left(u_{F}\left(k_{F}-k_{T}\right)\right)^{2}}}{2 k_{F}} \\
& =\frac{u_{F}\left(k_{F}-k_{T}\right)+u_{F}\left(k_{F}-k_{T}\right)}{2 k_{F}}=u_{F} \frac{k_{F}-k_{T}}{k_{F}} .
\end{aligned}
$$

Next we prove the right part of the inequality as follows,

$$
\begin{aligned}
X_{F 2}^{*} & =\frac{u_{F}\left(k_{F}-k_{T}\right)+\sqrt{\left(u_{F}\left(k_{F}-k_{T}\right)\right)^{2}+4 k_{F} k_{T} u_{F} u_{L}}}{2 k_{F}} \\
& <\frac{u_{F}\left(k_{F}-k_{T}\right)+\sqrt{\left(u_{F}\left(k_{F}-k_{T}\right)\right)^{2}+4 k_{F} k_{T} u_{F} u_{F}}}{2 k_{F}} \\
& =\frac{u_{F}\left(k_{F}-k_{T}\right)+u_{F}\left(k_{F}+k_{T}\right)}{2 k_{F}}=u_{F} .
\end{aligned}
$$

(b) Here we only prove the left part of the inequality in the case $k_{F}>k_{T}$ since the right part is the same as above.

$$
\begin{aligned}
X_{F 2}^{*} & =\frac{u_{F}\left(k_{F}-k_{T}\right)+\sqrt{\left(u_{F}\left(k_{F}-k_{T}\right)\right)^{2}+4 k_{F} k_{T} u_{F} u_{L}}}{2 k_{F}} \\
& >\frac{u_{F}\left(k_{F}-k_{T}\right)+\sqrt{\left(u_{L}\left(k_{F}-k_{T}\right)\right)^{2}+4 k_{F} k_{T} u_{L} u_{L}}}{2 k_{F}} \\
& =\frac{u_{F}\left(k_{F}-k_{T}\right)+u_{L}\left(k_{F}+k_{T}\right)}{2 k_{F}} .
\end{aligned}
$$

Since in this case $k_{F}>k_{T}$ then

$$
X_{F 2}^{*}>\frac{u_{L}\left(k_{F}-k_{T}\right)+u_{L}\left(k_{F}+k_{T}\right)}{2 k_{F}}=u_{L} .
$$

(2) Case $u_{F}<u_{L}$ 
(a) First we prove the left part of the inequality in the general case,

$$
\begin{aligned}
X_{F 2}^{*} & =\frac{u_{F}\left(k_{F}-k_{T}\right)+\sqrt{\left(u_{F}\left(k_{F}-k_{T}\right)\right)^{2}+4 k_{F} k_{T} u_{F} u_{L}}}{2 k_{F}} \\
& >\frac{u_{F}\left(k_{F}-k_{T}\right)+\sqrt{\left(u_{F}\left(k_{F}-k_{T}\right)\right)^{2}+4 k_{F} k_{T} u_{F} u_{F}}}{2 k_{F}} \\
& =\frac{u_{F}\left(k_{F}-k_{T}\right)+u_{F}\left(k_{F}+k_{T}\right)}{2 k_{F}}=u_{F} .
\end{aligned}
$$

Next we prove the right part of the inequality as follows,

$$
\begin{aligned}
X_{F 2}^{*} & =\frac{u_{F}\left(k_{F}-k_{T}\right)+\sqrt{\left(u_{F}\left(k_{F}-k_{T}\right)\right)^{2}+4 k_{F} k_{T} u_{F} u_{L}}}{2 k_{F}} \\
& <\frac{u_{F}\left(k_{F}-k_{T}\right)+\sqrt{\left(u_{L}\left(k_{F}-k_{T}\right)\right)^{2}+4 k_{F} k_{T} u_{L} u_{L}}}{2 k_{F}} \\
& =\frac{u_{F}\left(k_{F}-k_{T}\right)+u_{L}\left(k_{F}+k_{T}\right)}{2 k_{F}}<\frac{u_{F}\left(k_{F}+k_{T}\right)+u_{L}\left(k_{F}+k_{T}\right)}{2 k_{F}} \\
& <\frac{u_{L}\left(k_{F}+k_{T}\right)+u_{L}\left(k_{F}+k_{T}\right)}{2 k_{F}}=u_{L} \frac{k_{F}+k_{T}}{k_{F}} .
\end{aligned}
$$

(b) Here we only prove the right part of the inequality in the case of $k_{F}<k_{T}$ since the left part is the same as above.

$$
\begin{aligned}
X_{F 2}^{*} & =\frac{u_{F}\left(k_{F}-k_{T}\right)+\sqrt{\left(u_{F}\left(k_{F}-k_{T}\right)\right)^{2}+4 k_{F} k_{T} u_{F} u_{L}}}{2 k_{F}} \\
& <\frac{u_{F}\left(k_{F}-k_{T}\right)+\sqrt{\left(u_{L}\left(k_{F}-k_{T}\right)\right)^{2}+4 k_{F} k_{T} u_{L} u_{L}}}{2 k_{F}} \\
& =\frac{u_{F}\left(k_{F}-k_{T}\right)+u_{L}\left(k_{F}+k_{T}\right)}{2 k_{F}} .
\end{aligned}
$$

Since in this case $k_{F}>k_{T}$ then

$$
X_{F 2}^{*}<\frac{u_{L}\left(k_{F}-k_{T}\right)+u_{L}\left(k_{F}+k_{T}\right)}{2 k_{F}}=u_{L} .
$$

(3) Case $u_{F}=u_{L}$ Let $k_{F}=n k_{T}$ with $n>0$ then

$$
\begin{aligned}
X_{F 2}^{*} & =\frac{u_{F}\left(k_{F}-k_{T}\right)+\sqrt{\left(u_{F}\left(k_{F}-k_{T}\right)\right)^{2}+4 k_{F} k_{T} u_{F} u_{L}}}{2 k_{F}} \\
& =\frac{u_{L}\left((n-1) k_{T}\right)+\sqrt{\left(u_{L}\left((n-1) k_{T}\right)\right)^{2}+4 n k_{T} k_{T} u_{L} u_{L}}}{2 n k_{T}} \\
& =\frac{u_{L}\left((n-1) k_{T}\right)+\sqrt{\left(u_{L}\left((n+1) k_{T}\right)\right)^{2}}}{2 n k_{T}}=u_{L} .
\end{aligned}
$$

Note that in the model above, in the absence of technology transfer from the leader, i.e. when $k_{T}=0$, the maximum technological development of the follower will reach 
the maximum level $u_{F}$ eventually, regardless the technological development level of the leader. However, in the presence of technological transfer, Propositions 2.1-2.3 show this is true only if $u_{F}=u_{L}$. In this case there is a trade-off among the leader and follower parameters. The Proposition 2.4 uncovers more results regarding the trade-off for some spesific parameters.

Proposition 2.4. Let $u_{F}=m u_{L}$ and $k_{F}=n k_{T}$, with $m, n>0$, the stable steady state solution $\left(X_{L 2}^{*}, X_{F 2}^{*}\right)$ has the following properties:

(1) If $m=n$ then $X_{F 2}^{*}=m u_{L}$,

(2) If $m>n$ then $n u_{L}<X_{F 2}^{*}<\left(\frac{m}{n}\right) u_{L}$,

(3) If $m<n$ then $\left(\frac{m}{n}\right) u_{L}<X_{F 2}^{*}<n u_{L}$,

(4) If $m=1$ then $X_{F 2}^{*}=u_{L}$,

(5) If $n=1$ then $X_{F 2}^{*}=\sqrt{m} u_{L}$.

ProOF.

(1)

$$
\begin{aligned}
X_{F 2}^{*} & =\frac{m u_{L}\left(n k_{T}-k_{T}\right)+\sqrt{\left(m u_{L}\left(n k_{T}-k_{T}\right)\right)^{2}+4 n k_{T} k_{T} m u_{L} u_{L}}}{2 k_{F}} \\
& =\frac{m(n-1) k_{T} u_{L}+\sqrt{\left(m(n-1) k_{T} u_{L}\right)^{2}+4 m n\left(k_{T} u_{L}\right)^{2}}}{2 k_{F}} \\
& =\frac{(m(n-1)+m(n+1)) k_{T} u_{L}}{2 n k_{T}}=m u_{L} .
\end{aligned}
$$

(2)

$$
\begin{aligned}
X_{F 2}^{*} & =\frac{m u_{L}\left(n k_{T}-k_{T}\right)+\sqrt{\left(m u_{L}\left(n k_{T}-k_{T}\right)\right)^{2}+4 n k_{T} k_{T} m u_{L} u_{L}}}{2 k_{F}} \\
& >\frac{n(n-1) k_{T} u_{L}+\sqrt{\left(n(n-1) k_{T} u_{L}\right)^{2}+4 n n\left(k_{T} u_{L}\right)^{2}}}{2 k_{F}} \\
& =\frac{(n(n-1)+n(n+1)) k_{T} u_{L}}{2 n k_{T}}=n u_{L} .
\end{aligned}
$$

On the other hand we also have

$$
\begin{aligned}
X_{F 2}^{*} & =\frac{m u_{L}\left(n k_{T}-k_{T}\right)+\sqrt{\left(m u_{L}\left(n k_{T}-k_{T}\right)\right)^{2}+4 n k_{T} k_{T} m_{u_{L}} u_{L}}}{2 k_{F}} \\
& <\frac{m(m-1) k_{T} u_{L}+\sqrt{\left(m(m-1) k_{T} u_{L}\right)^{2}+4 m m\left(k_{T} u_{L}\right)^{2}}}{2 k_{F}} \\
& =\frac{(m(m-1)+m(m+1)) k_{T} u_{L}}{2 n k_{T}}=\left(\frac{m}{n}\right) u_{L} .
\end{aligned}
$$


(3)

$$
\begin{aligned}
X_{F 2}^{*} & =\frac{m u_{L}\left(n k_{T}-k_{T}\right)+\sqrt{\left(m u_{L}\left(n k_{T}-k_{T}\right)\right)^{2}+4 n k_{T} k_{T} m u_{L} u_{L}}}{2 k_{F}} \\
& <\frac{n(n-1) k_{T} u_{L}+\sqrt{\left(n(n-1) k_{T} u_{L}\right)^{2}+4 n n\left(k_{T} u_{L}\right)^{2}}}{2 k_{F}} \\
& =\frac{(n(n-1)+n(n+1)) k_{T} u_{L}}{2 n k_{T}}=n u_{L} .
\end{aligned}
$$

On the other hand we also have

$$
\begin{aligned}
X_{F 2}^{*} & =\frac{m u_{L}\left(n k_{T}-k_{T}\right)+\sqrt{\left(m u_{L}\left(n k_{T}-k_{T}\right)\right)^{2}+4 n k_{T} k_{T} m u_{L} u_{L}}}{2 k_{F}}, \\
& >\frac{m(m-1) k_{T} u_{L}+\sqrt{\left(m(m-1) k_{T} u_{L}\right)^{2}+4 m m\left(k_{T} u_{L}\right)^{2}}}{2 k_{F}}, \\
& =\frac{(m(m-1)+m(m+1)) k_{T} u_{L}}{2 m k_{T}}=\left(\frac{m}{n}\right) u_{L} .
\end{aligned}
$$

(4) It is clear from result (1) of the proposition.

(5) It is clear from the definition of $X_{F 2}^{*}$.

Note that Proposition 2.4 implies the maximum level of the follower technological development is given by $X_{F 2}^{*} \leq \max \left(u_{F}, u_{L}\right)$. In the next section we presents some examples to illustrate the results described in the propositions.

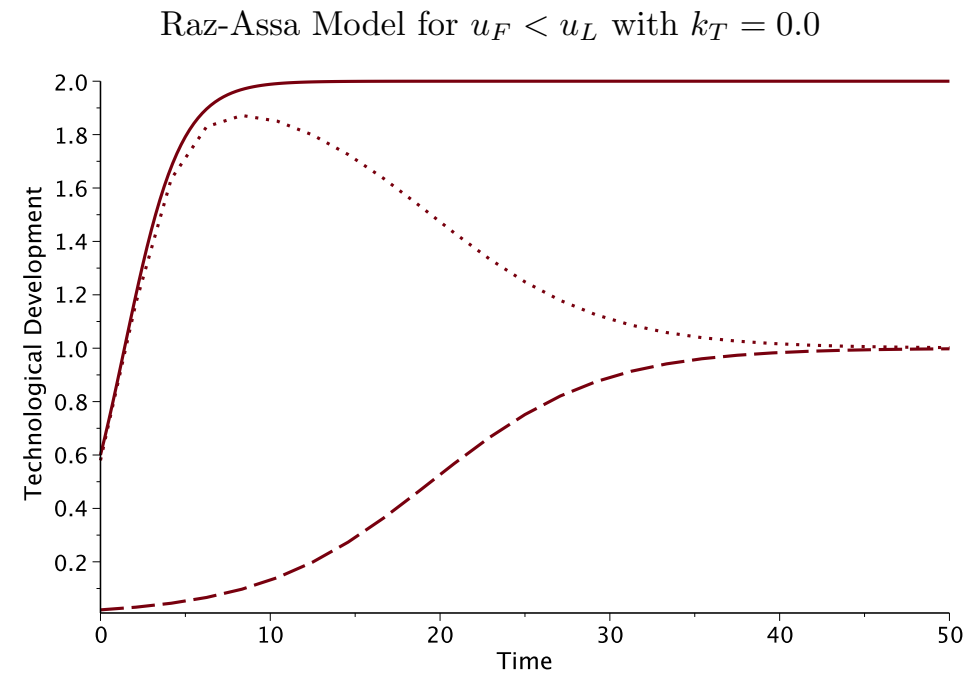

Figure 1. Plots of $X_{L}(t)$ (solid), $X_{F}(t)$ (dash), and $X_{L}(t)-X_{F}(t)(\operatorname{dots})$ with $u_{F}=1$, $u_{L}=2, k_{T}=0$. 


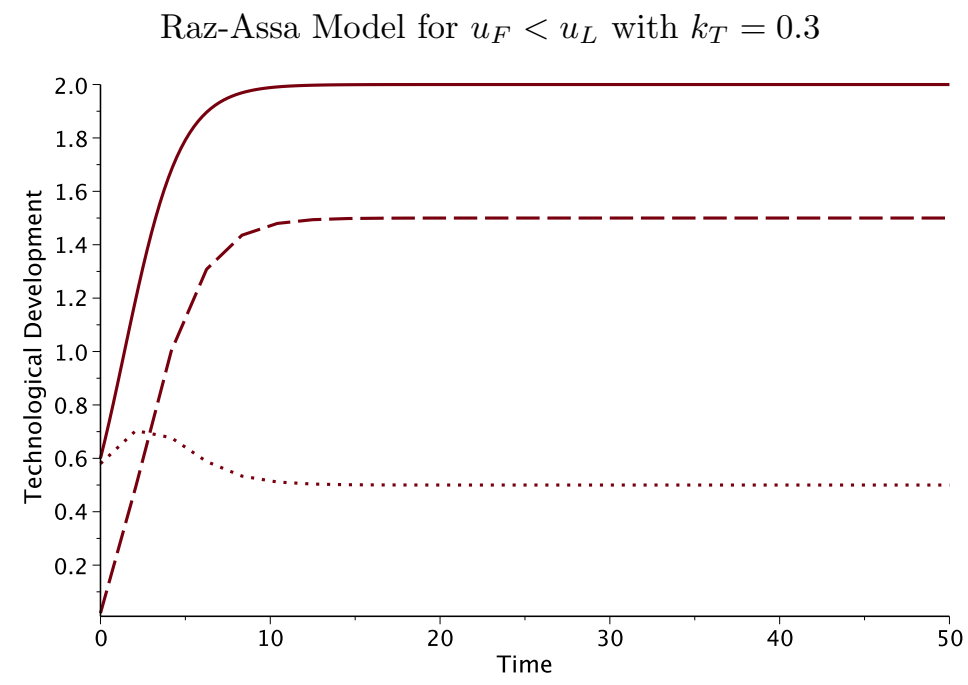

Figure 2. Plots of $X_{L}(t)$ (solid), $X_{F}(t)$ (dash), and $X_{L}(t)-X_{F}(t)$ (dots) with $u_{F}=1$, $u_{L}=2, k_{T}=0.3$.

2.1. Numerical Examples of Raz and Assa Coupled Logistic Model. Figure 1 shows the plots of the leader technological development $X_{L}$ (solid) and the follower technological development $X_{F}$ (dash) with respect to time, as the solution of equations (7) and (8), respectively. Dots represent the technological gap between the leader and the follower. The parameters used in this example are taken from [19] (except that $k_{T}=0$ ), i.e. $k_{L}=0.6, k_{F}=0.2, u_{L}=2, u_{f}=1$ with the initial states of the technological development are $X_{L}(0)=0.6$ and $X_{F}(0)=0.02$. Figure 2 shows the solution to the same situation but in this case there is a transfer technology from the leader to the follower with $k_{T}=0.3$. Note that the maximum technological development of the follower is now above its original upper limit $\left(u_{F}=1\right.$ and $X_{F 2}^{*}$ is about 1.5) due to the presence of the technology transfer.

Next we assume the following situation. Both parties, say $L$ and $F$, develop a certain technology independently, with the same parameters as above, except the values of $u_{L}$ and $u_{F}$ are reversed, i.e., $u_{L}=1$ and $u_{F}=2$, and they begin from the same initial condition, i.e. $X_{L}(0)=X_{F}(0)=0.02$. The solution to this problem in the absence of technology transfer is illustrated by Figure 3. Furthermore, if $L$ is heading in this technological contest compared to $L$, e.g. $X_{L}(0)=0.6$ and $X_{F}(0)=0.02$, then we have Figure 4 as the illustration. Next suppose that since $F$ is lagged behind, in terms of the innitiation of the technological implementation, and there is a transfer technology from $L$ to $F$ with $k_{T}=0.3$, then the development of technology of the two parties is depicted by Figure 5. Surprisingly, in the long term, the condition for the follower is worse compared to the situation in which there is no technology transfer. In this case the follower cannot attain its original upper limit technological development. This is somewhat paradoxial. In the next section we propose alternative models to overcome this limitation by assuming that the 
presence of technology transfer together with the gap of technological development affect the follower rate of development.

Raz-Assa Model for $u_{F}>u_{L}$ with $k_{T}=0.0$ [the same initial conditions]

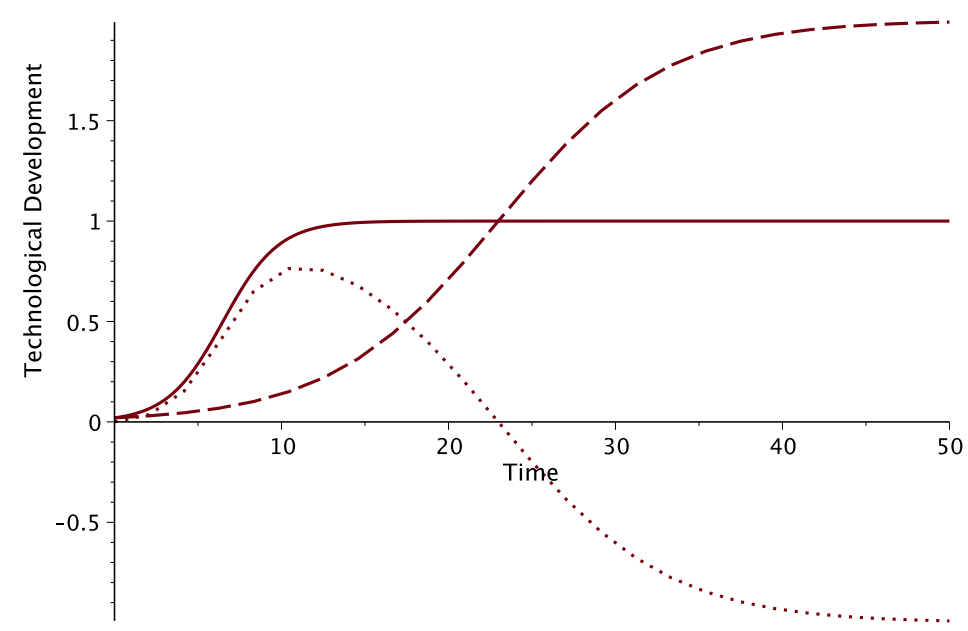

Figure 3. Plots of $X_{L}(t)$ (solid), $X_{F}(t)$ (dash), and $X_{L}(t)-X_{F}(t)$ (dots) with $u_{F}=2$, $u_{L}=1, k_{T}=0$.

Raz-Assa Model for $u_{F}>u_{L}$ with $k_{T}=0.0$ [different initial conditions]

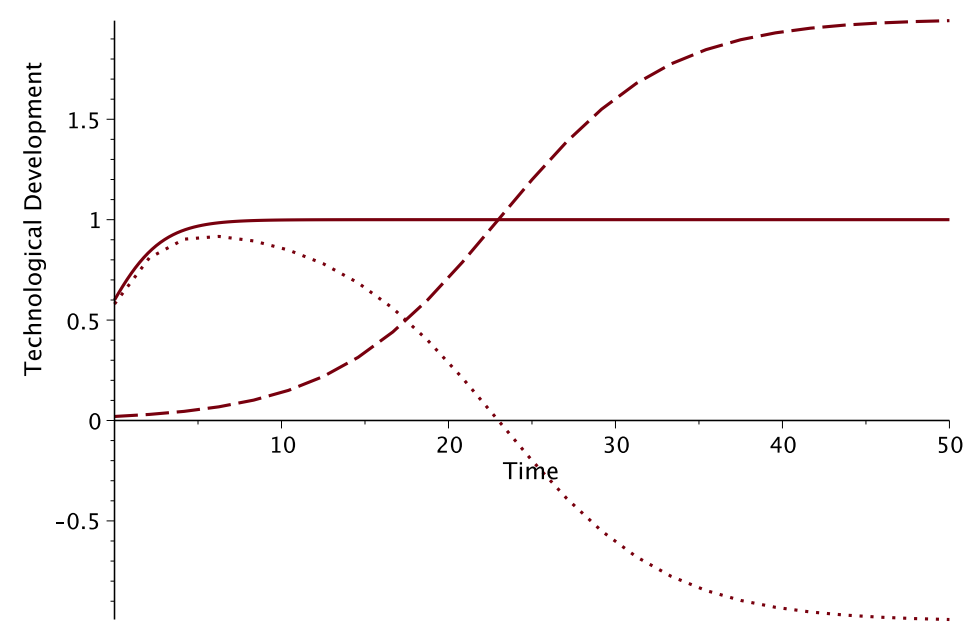

Figure 4. Plots of $X_{L}(t)$ (solid), $X_{F}(t)$ (dash), and $X_{L}(t)-X_{F}(t)$ (dots) with $u_{F}=2$, $u_{L}=1, k_{T}=0$. 
Raz-Assa Model for $u_{F}>u_{L}$ with $k_{T}=0.3$

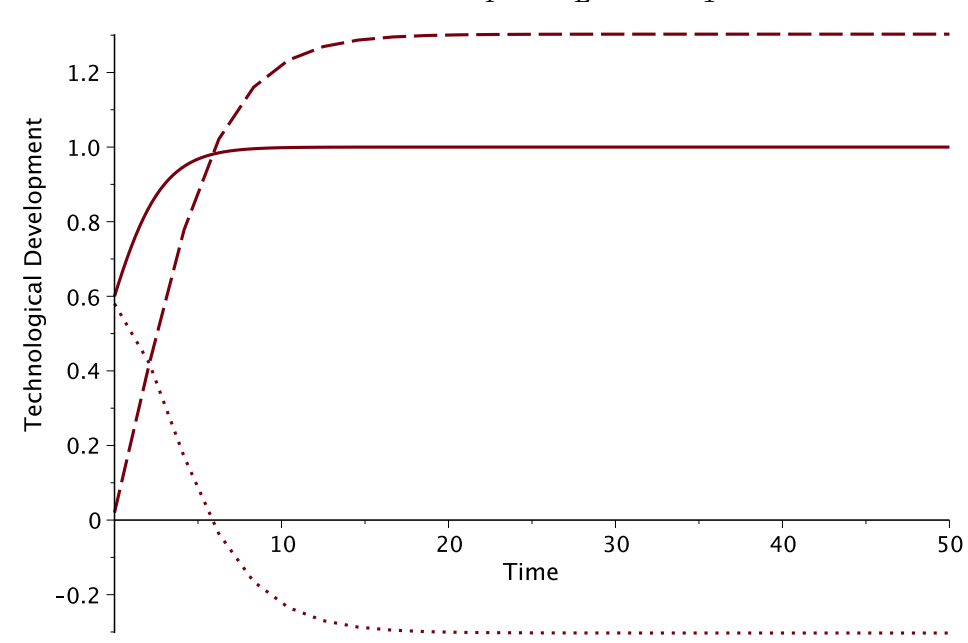

Figure 5. Plots of $X_{L}(t)$ (solid), $X_{F}(t)$ (dash), and $X_{L}(t)-X_{F}(t)$ (dots) with $u_{F}=2$, $u_{L}=1, k_{T}=0.3$. The case where the paradox of technology transfer occurs.

\section{Modification of the Raz and Assa Coupled logistic Model}

3.1. The First Modified Model. The first revision to the model is done by assuming that the presence of technology transfer affects the follower's ability to develop $k_{F}$. Hence the model is given by equations (9) and (10) with the results presented in Propositions 3.1.1-3.1.2.

$$
\begin{gathered}
\frac{d X_{L}(t)}{d t}=k_{L} X_{L}(t)\left(1-\frac{X_{L}(t)}{u_{L}}\right), \\
\frac{d X_{F}(t)}{d t}=\left(1+k_{T}\left(X_{L}(t)-X_{F}(t)\right)\right) k_{F} X_{F}(t)\left(1-\frac{X_{F}(t)}{u_{F}}\right),
\end{gathered}
$$

Proposition 3.1. The system of equations (9) and (10) has six steady state solutions with exactly two positive co-existence steady state solution.

Proof. It is clear that by equating both equations (9) and (10) to zero and solve for $x_{L}$ and $x_{F}$ we found six steady states, namely $\left(X_{L 0}^{*}, X_{F 0}^{*}\right)=(0,0),\left(X_{L 1}^{*}, X_{F 1}^{*}\right)=$ $\left(0, u_{F}\right),\left(X_{L 2}^{*}, X_{F 2}^{*}\right)=\left(0,1 / k_{T}\right),\left(X_{L 3}^{*}, X_{F 3}^{*}\right)=\left(u_{L}, 0\right),\left(X_{L 4}^{*}, X_{F 4}^{*}\right)=\left(u_{L}, u_{F}\right)$, and $\left(X_{L 5}^{*}, X_{F 5}^{*}\right)=\left(u_{L}, \frac{1+k_{T} u_{L}}{k_{T}}\right)$. This completes the proof.

Proposition 3.2. The positive steady state solution $\left(X_{L 4}^{*}, X_{F 4}^{*}\right)=\left(u_{L}, u_{F}\right)$ is stable and $\left(X_{L 5}^{*}, X_{F 5}^{*}\right)=\left(u_{L}, \frac{1+k_{T} u_{L}}{k_{T}}\right)$ is unstable whenever $T_{0}=k_{T}\left(u_{F}-u_{L}\right)<1$. The converse is true otherwise. All other steady states are unstable, regardless the value of $k_{T}\left(u_{F}-u_{L}\right)$. 
Proof.

(1) The eigen values of the Jacobian matrix for $\left(X_{L 0}^{*}, X_{F 0}^{*}\right)$ are $k_{L}$ and $k_{F}$, which is all positive.

(2) The eigen values of the Jacobian matrix for $\left(X_{L 1}^{*}, X_{F 1}^{*}\right)$ are $k_{L}$ and $k_{F}\left(k_{T} u_{F}-\right.$ 1 ), which is not all negative.

(3) The eigen values of the Jacobian matrix for $\left(X_{L 2}^{*}, X_{F 2}^{*}\right)$ are $k_{L}$ and $\frac{k_{F}\left(k_{T} u_{F}-1\right)}{k_{T} u_{F}}$, which is not all negative.

(4) The eigen values of the Jacobian matrix for $\left(X_{L 3}^{*}, X_{F 3}^{*}\right)$ are $-k_{L}$ and $k_{F}(1+$ $k_{t} u_{L}$ ), which is not all negative.

(5) The eigen values of the Jacobian matrix for $\left(X_{L 4}^{*}, X_{F 4}^{*}\right)$ are $-k_{L}$ and $-k_{F}-$ $k_{F} k_{T} u_{L}+k_{F} k_{T} u_{F}$. Note that $-k_{F}-k_{F} k_{T} u_{L}+k_{F} k_{T} u_{F}=k_{F}\left(k_{T}\left(u_{F}-\right.\right.$ $\left.\left.u_{L}\right)-1\right)=k_{F}\left(T_{0}-1\right)$, hence it is negative whenever $T_{0}<1$, means that the steady state is stable. Otherwise, if $T_{0}>1$ then the eigen value is positive, means that the steady state is unstable.

(6) The eigen values of the Jacobian matrix for $\left(X_{L 5}^{*}, X_{F 5}^{*}\right)$ are $-k_{L}$ and $\lambda_{42}=$ $\frac{k_{F}\left(1+2 k_{T} u_{L}-k_{T} u_{F}+k_{T}^{2} u_{L}^{2}-k_{T}^{2} u_{L} u_{F}\right)}{k_{T} u_{F}}$. The later can be simplified into

$$
\begin{aligned}
\lambda_{42} & =\frac{k_{F}\left(1+k_{T}\left(2 u_{L}-u_{F}-k_{T}\left(u_{F}-u_{L}\right) u_{L}\right)\right)}{k_{T} u_{F}} \\
& =\frac{k_{F}\left(1+k_{T}\left(2 u_{L}-u_{F}-T_{0} u_{L}\right)\right)}{k_{T} u_{F}}=\frac{k_{F}\left(1+k_{T}\left(\left(2-T_{0}\right) u_{L}-u_{F}\right)\right)}{k_{T} u_{F}} \\
& =\frac{k_{F}\left(1-k_{T}\left(\left(u_{F}-\left(2-T_{0}\right) u_{L}\right)\right)\right.}{k_{T} u_{F}} .
\end{aligned}
$$

Note that the sign of $\lambda_{42}$ depends on $T_{0}$. In the case of $T_{0}<1$ we have

$$
\begin{aligned}
\lambda_{42} & =\frac{k_{F}\left(1-k_{T}\left(\left(u_{F}-\left(2-T_{0}\right) u_{L}\right)\right)\right.}{k_{T} u_{F}} \\
& >\frac{k_{F}\left(1-k_{T}\left(\left(u_{F}-u_{L}\right)\right)\right.}{k_{T} u_{F}}=\frac{k_{F}\left(1-T_{0}\right)}{k_{T} u_{F}}>0,
\end{aligned}
$$

means that this steady state is unstable. Meanwhile, in the case of $T_{0}>1$ we have

$$
\begin{aligned}
\lambda_{42} & =\frac{k_{F}\left(1-k_{T}\left(\left(u_{F}-\left(2-T_{0}\right) u_{L}\right)\right)\right.}{k_{T} u_{F}} \\
& <\frac{k_{F}\left(1-k_{T}\left(\left(u_{F}-u_{L}\right)\right)\right.}{k_{T} u_{F}}=\frac{k_{F}\left(1-T_{0}\right)}{k_{T} u_{F}}<0,
\end{aligned}
$$

means that this steady state is stable.

3.2. Numerical Examples of the First Modified Model. In this section we give numerical examples with the same parameters as in previous examples. 
Modified Logistic Model for $u_{F}<u_{L}$ with $k_{T}=0.0$

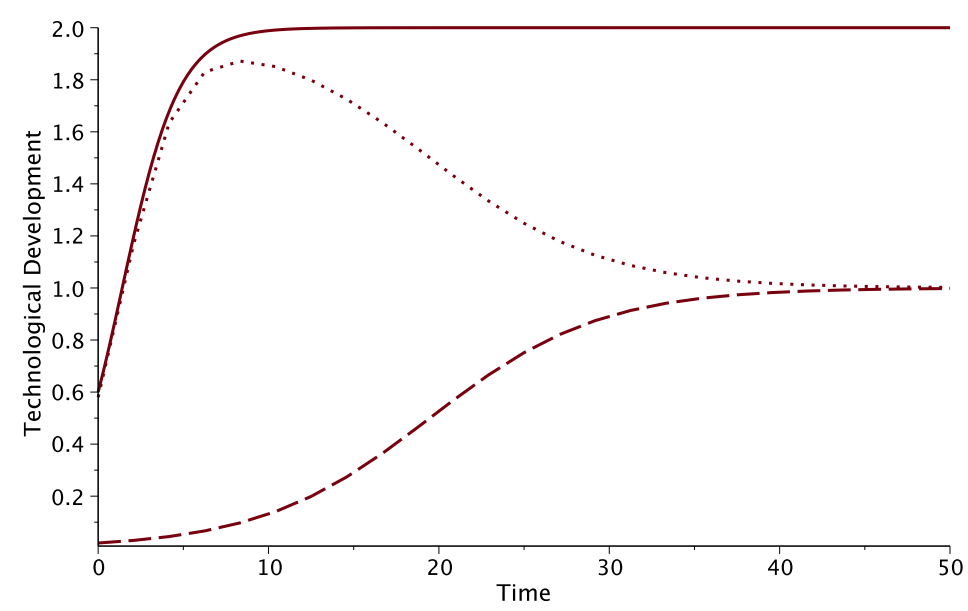

Figure 6. Plots of $X_{L}(t)$ (solid), $X_{F}(t)$ (dash), and $X_{L}(t)-X_{F}(t)$ (dots) with $u_{F}=1$, $u_{L}=2, k_{T}=0$.

Modified Logistic Model for $u_{F}<u_{L}$ with $k_{T}=0.3$

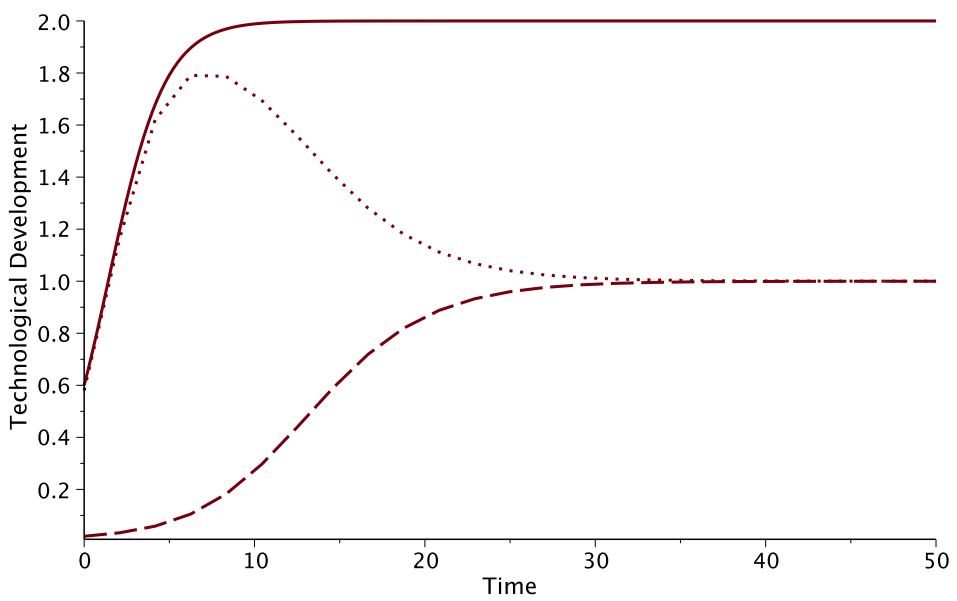

Figure 7. Plots of $X_{L}(t)$ (solid), $X_{F}(t)\left(\right.$ dash), and $X_{L}(t)-X_{F}(t)$ (dots) with $u_{F}=1$, $u_{L}=2, k_{T}=0.3$.

Figure 6 shows the plots of the leader technological development $X_{L}$ (solid) and the follower technological development $X_{F}$ (dash) with respect to time, as the solution of equations (9) and (10), respectively. Dots represent the technological gap between the leader and the follower. As before, the parameters used in this example are taken from [19] (except that $k_{T}=0$ ), i.e. $k_{L}=0.6, k_{F}=0.2, u_{L}=2$, $u_{F}=1$ with the initial states of the technological development are $X_{L}(0)=0.6$ 
and $X_{F}(0)=0.02$. Figure 7 shows the solution to the same situation but in this case there is a transfer technology from the leader to the follower with $k_{T}=0.3$. Note that the maximum technological development of the follower is the same as before, i.e. $X_{F 2}^{*}=u_{F}=1$, but it is reached relatively faster than in the absence of technology transfer.

Next we assume the following situation. Both parties, say $L$ and $F$, develop a certain technology independently, with the same parameters as above, except the values of $u_{L}$ and $u_{F}$ are reversed, i.e., $u_{L}=1$ and $u_{F}=2$, and they begin to develop from the same initial condition, i.e. $X_{L}(0)=X_{F}(0)=0.02$. The solution to this problem in the absence of technology transfer is illustrated by Figure 8. Furthermore, if $L$ is heading in this technological contest compared to $L$, e.g. $X_{L}(0)=0.6$ and $X_{F}(0)=0.02$, then we have Figure 9 as the illustration. Next suppose that since $F$ is lagged behind, in terms of the innitiation of the technological implementation, and there is a transfer technology from $L$ to $F$ with $k_{T}=0.3$, then the development of technology of the two parties is depicted by Figure 10. Different from prediction derived by the original model, in which the follower cannot attain its original upper limit of technological development $u_{F}$, here $u_{F}$ can be attained in a faster time (Figure 10) compared to the time needed in the absence of technology transfer (Figure 9). Figure 10 also illustrates the stability of $u_{F}$ since $T_{0}=0.3<1$ (see Proposition 3.2 and also Figures 11 and 12).

Modified Logistic Model for $u_{F}>u_{L}$ with $k_{T}=0.0$ [the same initial conditions]

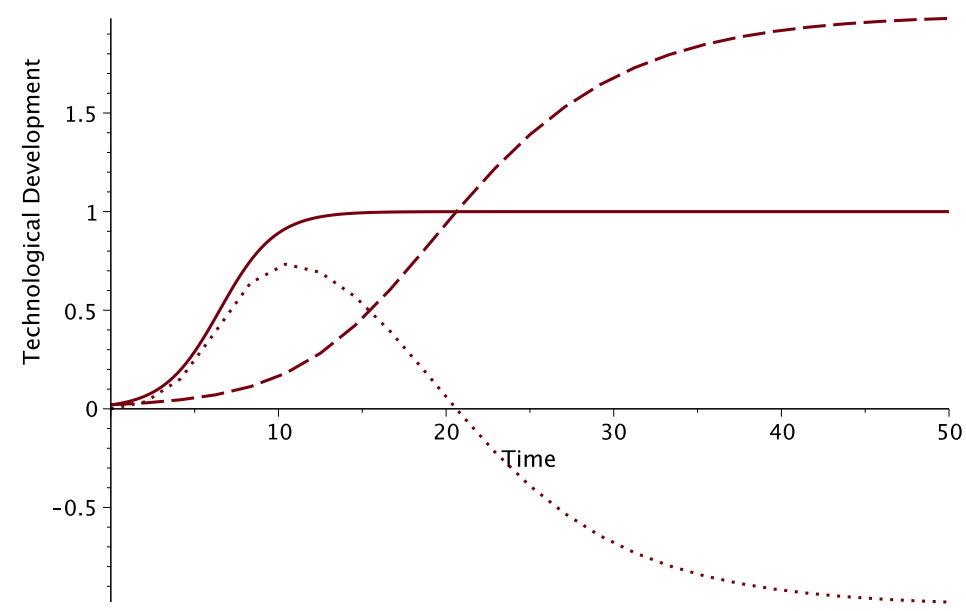

Figure 8. Plots of $X_{L}(t)$ (solid), $X_{F}(t)$ (dash), and $X_{L}(t)-X_{F}(t)$ (dots) with $u_{F}=2$, $u_{L}=1, k_{T}=0$.

Note that by referring to the proof of Proposition 3.2, there is a switching of stability between $\left(X_{L 4}^{*}, X_{F 4}^{*}\right)$ and $\left(X_{L 5}^{*}, X_{F 5}^{*}\right)$ depending on the value of $T_{0}$, hence the value $T_{0}=k_{T}\left(u_{F}-u_{L}\right)$ is a stability threshold. The figures show that in a ceterus paribus condition, the increase of technology transfer rate causes the loose 
Modified Logistic Model for $u_{F}>u_{L}$ with $k_{T}=0.0$ [different initial conditions]

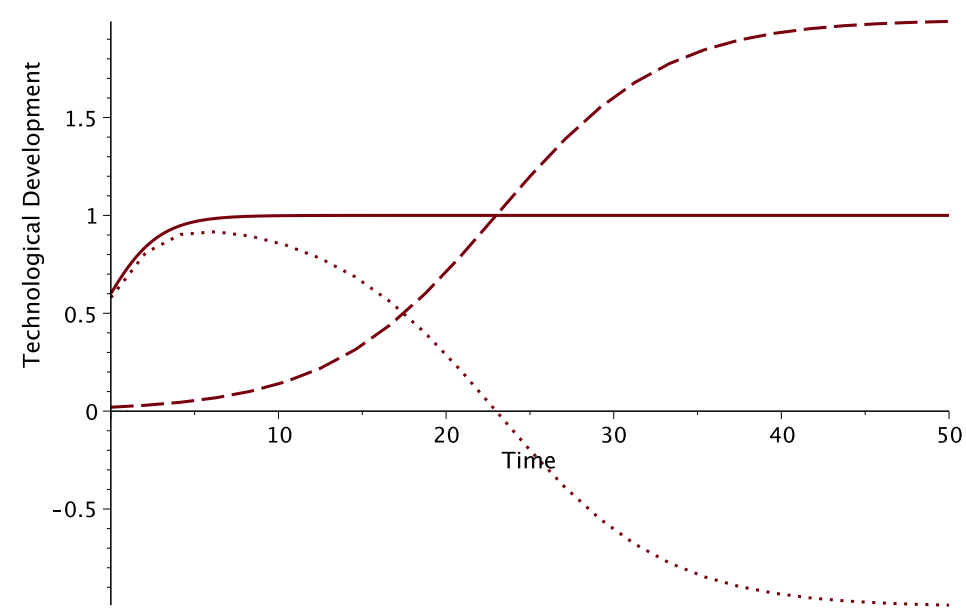

Figure 9. Plots of $X_{L}(t)$ (solid), $X_{F}(t)$ (dash), and $X_{L}(t)-X_{F}(t)$ (dots) with $u_{F}=2$, $u_{L}=1, k_{T}=0$.

Modified Logistic Model for $u_{F}>u_{L}$ with $k_{T}=0.3$

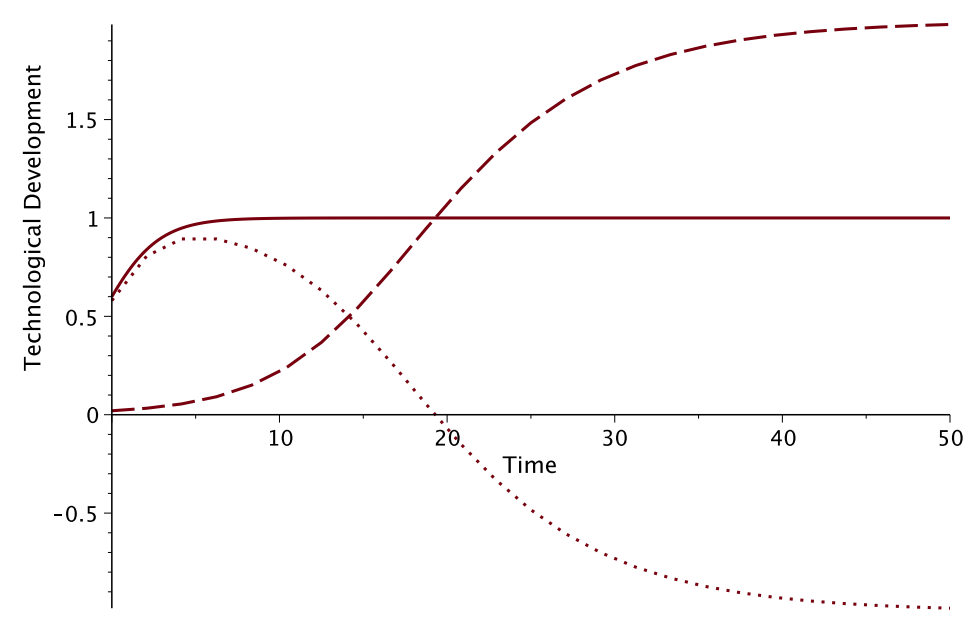

Figure 10. Plots of $X_{L}(t)$ (solid), $X_{F}(t)$ (dash), and $X_{L}(t)-X_{F}(t)$ (dots) with $u_{F}=2$, $u_{L}=1, k_{T}=0.3$. In this case the threshold $T_{0}=0.3<1$, hence $\left(u_{L}, u_{F}\right)$ is stable.

of the stability of the maximum level of the follower development capacity. In fact for a very high technology transfer rate, it approaches the maximum level of the leader as indicated by the following expression limit $k_{T} \rightarrow \infty \Rightarrow \frac{1+k_{T} u_{L}}{k_{T}} \rightarrow u_{L}$. Figure 13 reveals that for a very high technology transfer rate, the paradox in the original model still appear. As is the original model, it is plausible to argue that 
Modified Logistic Model for $u_{F}>u_{L}$ with $k_{T}=0.9$

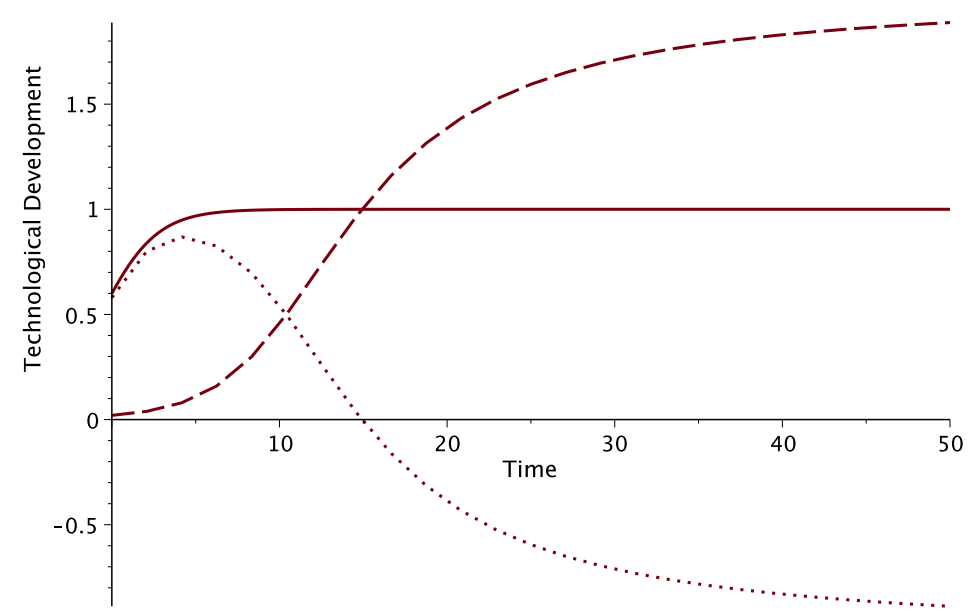

Figure 11. Plots of $X_{L}(t)$ (solid), $X_{F}(t)$ (dash), and $X_{L}(t)-X_{F}(t)$ (dots) with $u_{F}=2$, $u_{L}=1, k_{T}=0.9$. In this case the threshold $T_{0}=0.9<1$, hence $\left(u_{L}, u_{F}\right)$ is stable, although it looks unstable. See Figure 12 for the long-term behaviour.

Modified Logistic Model for $u_{F}>u_{L}$ with $k_{T}=0.9$ [the long-term behaviour]

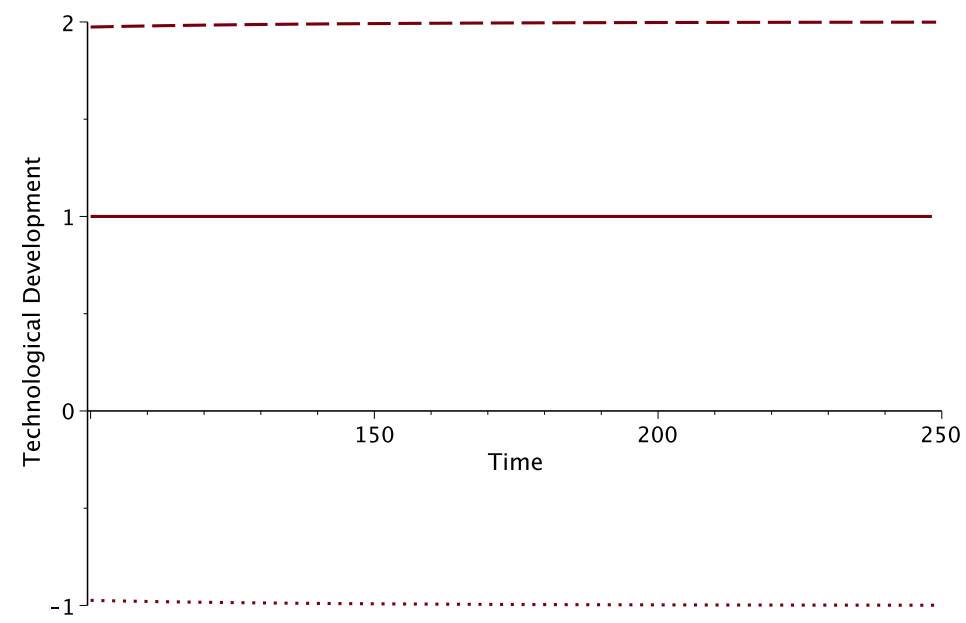

Figure 12. Plots of $X_{L}(t)$ (solid), $X_{F}(t)$ (dash), and $X_{L}(t)-X_{F}(t)$ (dots) with $u_{F}=2$, $u_{L}=1, k_{T}=0.9$ beyond 100 time course. It is clear, since the threshold $T_{0}=0.9<1$, the equilibrium state $\left(u_{L}, u_{F}\right)$ is stable.

the paradox is due to the presence of negative value of the technology gap between the leader and the follower. In the next section we propose an alternative model to overcome this limitation by assuming that the presence of technology transfer 
Modified Logistic Model for $u_{F}>u_{L}$ with $k_{T}=2$

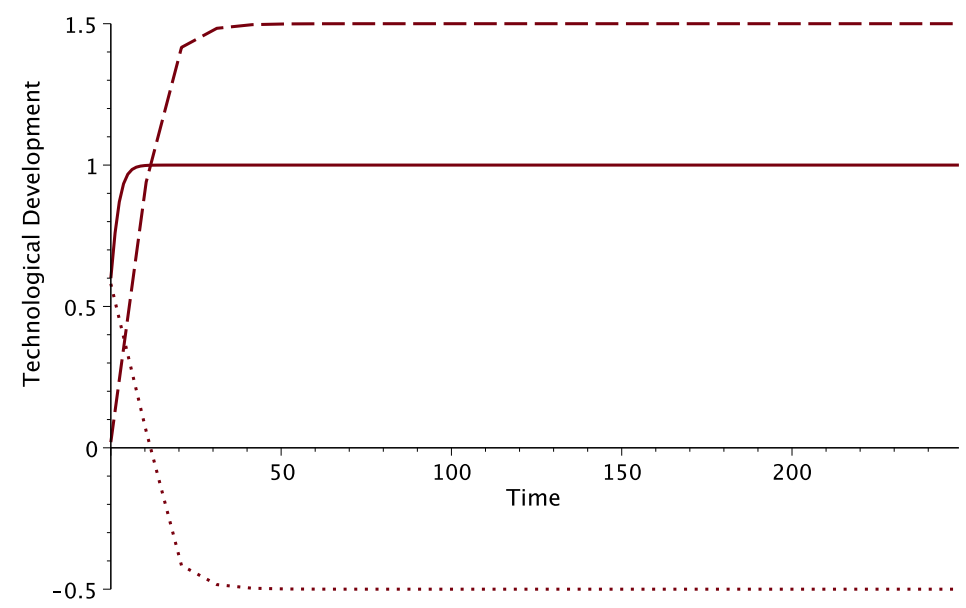

Figure 13. Plots of $X_{L}(t)$ (solid), $X_{F}(t)$ (dash), and $X_{L}(t)-X_{F}(t)$ (dots) with $u_{F}=2$, $u_{L}=1, k_{T}=2$. It is clear, since the threshold $T_{0}=2>1$, the equilibrium state $\left(u_{L}, u_{F}\right)$

is unstable. In this case the stable equilibrium state is $\left(u_{L}, \frac{1+k_{T} u_{L}}{k_{T}}\right)$ indicating the occurence of the technology transfer paradox.

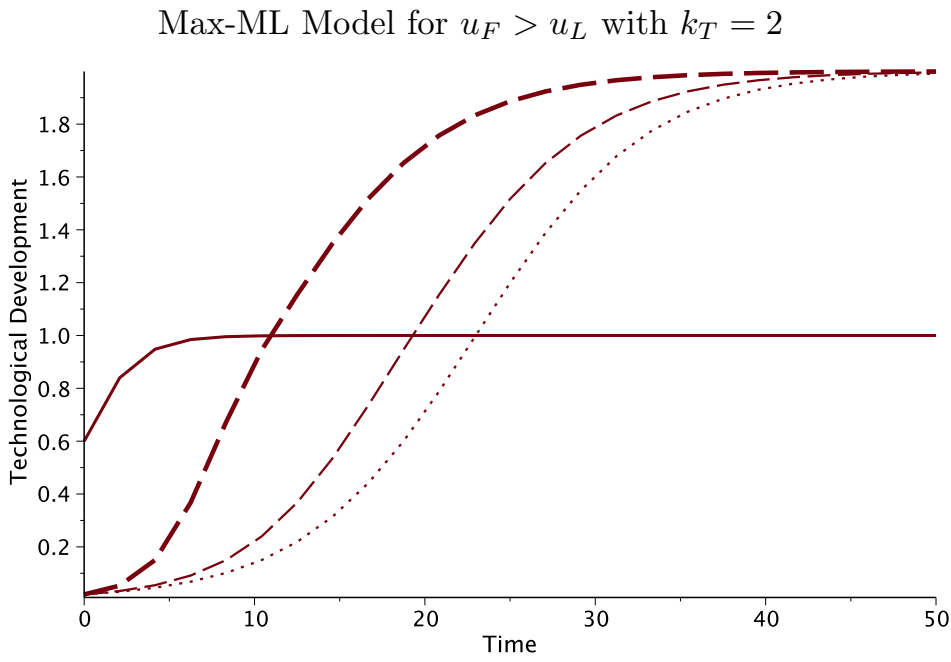

Figure 14. Trajectories of system 11 and 12 for three different transfer rates, i.e. $k_{T}=2,0.3$ and 0.0 , together with $u_{F}=2$ and $u_{L}=1$ (the other parameters are the same as in the previous examples). As it is expected the model gives a paradox-free result, in which technology transfer always enhances the growth of the follower.

explicitly has a non-negative impact in increasing the rate of development regardless the sign of the technology gap between the leader and the follower. 
3.3. The Second Modified Model. Here we assume that the presence of technology transfer explicitly has a non-negative impact in increasing the follower's rate of development. We call the model as the Maximum Modified Logistic (Max-ML) model with the governing equations given as follows,

$$
\begin{gathered}
\frac{d X_{L}(t)}{d t}=k_{L} X_{L}(t)\left(1-\frac{X_{L}(t)}{u_{L}}\right) \\
\frac{d X_{F}(t)}{d t}=\left(1+k_{T} \max \left(0,\left(X_{L}(t)-X_{F}(t)\right)\right)\right) k_{F} X_{F}(t)\left(1-\frac{X_{F}(t)}{u_{F}}\right) .
\end{gathered}
$$

The following propositions are the main results of the model's behaviour in terms of its equilibria. The propositions will show that the model rectifies/removes the occurence of the unwanted paradox appearing in the earlier models.

Proposition 3.3. The system of equations (11) and (12) has six steady state solutions with exactly two positive co-existence steady state solutions.

Proof. It is clear that by equating equation (11) to zero and solve for $X_{L}$ we found two solutions, namely $X_{L}^{*}=0$ and $X_{L}^{*}=u_{L}$. To find the steady state solution from equation (12), we have $\left(1+k_{T} \max \left(0,\left(X_{L}(t)-X_{F}(t)\right)\right)\right) k_{F} X_{F}(t)$ $\left(1-\frac{X_{F}(t)}{u_{F}}\right)=0$. We solve this equation for $X_{F}$, by looking at the following two cases, namely $X_{L}^{*}=0$ and $X_{L}^{*}=u_{L}$.

(1) Case $X_{L}^{*}=0$. We have $\left(1+\max \left(0, k_{T}\left(-X_{F}(t)\right)\right)\right) k_{F} X_{F}(t)\left(1-\frac{X_{F}(t)}{u_{F}}\right)=$ 0 , hence we obtain three solutions, $X_{F}^{*}=0, X_{F}^{*}=u_{F}$, and one solution from $\left(1+\max \left(0, k_{T}\left(-X_{F}(t)\right)\right)\right)=0$ which exists when $\max \left(0, k_{T}\left(-X_{F}(t)\right)\right)$ $=-k_{T} X_{F}(t)$ and satisfied by $X_{F}^{*}=\frac{1}{k_{T}}$. Consequently, the steady state solutions for the system in this case are: $\left(X_{L 0}^{*}, X_{F 0}^{*}\right)=(0,0),\left(X_{L 1}^{*}, X_{F 1}^{*}\right)=$ $\left(0, u_{F}\right)$, and $\left(X_{L 2}^{*}, X_{F 2}^{*}\right)=\left(0,1 / k_{T}\right)$.

(2) Case $X_{L}^{*}=u_{L}$. As above we obtain three solutions, $X_{F}^{*}=0, X_{F}^{*}=$ $u_{F}$, and one solution from $\left(1+\max \left(0, k_{T}\left(u_{L}-X_{F}(t)\right)\right)\right)=0$, i.e. $X_{F}^{*}=$ $\frac{1+k_{T} u_{L}}{k_{T}}$. Consequently, the steady state solutions for the system in this case are: $\left(X_{L 3}^{*}, X_{F 3}^{*}\right)=\left(u_{L}, 0\right),\left(X_{L 4}^{*}, X_{F 4}^{*}\right)=\left(u_{L}, u_{F}\right)$, and $\left(X_{L 5}^{*}, X_{F 5}^{*}\right)=$ $\left(u_{L}, \frac{1+k_{T} u_{L}}{k_{T}}\right)$.

These steady states exactly the same as for the previous model, with the positive co-existence given by the last two steady states. This completes the proof.

Proposition 3.4. The positive steady state solution $\left(X_{L 4}^{*}, X_{F 4}^{*}\right)=\left(u_{L}, u_{F}\right)$ is stable and $\left(X_{L 5}^{*}, X_{F 5}^{*}\right)=\left(u_{L}, \frac{1+k_{T} u_{L}}{k_{T}}\right)$ is unstable. 
Proof. First we will show that $\left(X_{L 4}^{*}, X_{F 4}^{*}\right)=\left(u_{L}, u_{F}\right)$ is stable. Note that the dynamic of the follower growth in equation (12) can be written in the form

$$
\frac{d X_{F}(t)}{d t}= \begin{cases}k_{F} X_{F}(t)\left(1-\frac{X_{F}(t)}{u_{F}}\right), & \text { for } X_{L} \leq X_{F}, \\ \left(1+k_{T}\left(X_{L}(t)-X_{F}(t)\right)\right) k_{F} X_{F}(t)\left(1-\frac{X_{F}(t)}{u_{F}}\right), & \text { for } X_{L}>X_{F} .\end{cases}
$$

Clearly $X_{L}^{*}=u_{L}$ is a stable steady state solution of equation (11). Furthermore, $X_{F}^{*}=u_{F}$ is a stable steady state solution of the first part of equation (13) whenever $X_{L} \leq X_{F}$. We will show that this is also the case whenever $X_{L}>X_{F}$. Suppose that the initial growth of the follower is $X_{F}(0)=X_{F}^{0}<X_{L}$. If $X_{L}>X_{F}$ then from the second part of equation (13) we have $\frac{d X_{F}(t)}{d t}>0$, that is $X_{F}$ grows. If during following the trajectory of the second part of equation (13) $X_{F}$ hits $u_{F}$ then $\frac{d X_{F}(t)}{d t}=0$, which means that the orbit is trapped by the stable steady state $X_{F}^{*}=u_{F}$. If it does not hit $u_{F}$ then it will be continue to increase until finally crosses $X_{L}$ at its maximum, i.e. $X_{L}^{*}=u_{L}$. Since now $X_{F}=X_{L}$, then the trajectory follows the first part of equation (13) and eventually trapped by $X_{F}^{*}=u_{F}$. This completes the assertion that $\left(X_{L 4}^{*}, X_{F 4}^{*}\right)=\left(u_{L}, u_{F}\right)$ is stable.

Next we will show that $\left(X_{L 5}^{*}, X_{F 5}^{*}\right)=\left(u_{L}, \frac{1+k_{T} u_{L}}{k_{T}}\right)$ is unstable. Suppose that the initial growth of the follower is $X_{F}(0)=X_{F}^{0}<\min \left(X_{L}, \frac{1+k_{T} u_{L}}{k_{T}}\right)$, then the trajectory of a solution of (12) emanating from this initial point will grow according to the second part of equation (13). This trajectory will never been trapped by $\left(X_{L 5}^{*}, X_{F 5}^{*}\right)=\left(u_{L}, \frac{1+k_{T} u_{L}}{k_{T}}\right)$, due to the fact that $\frac{1+k_{T} u_{L}}{k_{T}}>u_{L}$ for any positive value of transfer rate $k_{T}$. Hence, before it reaches $\frac{1+k_{T} u_{L}}{k_{T}}$, the point $u_{L}$ will be first encountered. This is the highest point of the leader's technological development $X_{L}(t)$, hence from this point onward the trajectory will grow according to the first part of equation (13), and finally trapped by the stable steady state $X_{F}^{*}=u_{F}$. This completes the assertion that $\left(X_{L 5}^{*}, X_{F 5}^{*}\right)=\left(u_{L}, \frac{1+k_{T} u_{L}}{k_{T}}\right)$ is unstable.

Figure 14 shows the trajectories of the system of equations (11) and (13) for three different transfer rates, i.e. $k_{T}=1.1,0.3$ and 0.0 , with the other parameters are the same as in the previous examples. When there is no technology transfer from the leader (thin dashes), $X_{L}$ develops according to its original growth rate and eventually its indigenous capability to develop brings to the upper limit of the technological development. When there is a very strong technology transfer rate (thick dashes), $X_{L}$ grows rapidly, i.e. reaches the upper limit of the technological development faster. The trajectory in between the previous two trajectories reflects a mild technology transfer from the leader.

\section{Concluding Remarks}

In this paper, we revisited a well-known mathematical model of coupled technology transfer. The analysis of the model is carried out via dynamical system approach. 
The model has implicitly assumed that in the absence of technology transfer, a follower has an ability to develop up to a certain maximum level of technological development. We found that in some circumstances, there is a paradoxial phenomenon predicted by the model, i.e. in the presence of technology transfer a strong dependence of the follower's technological growth rate on the leader's technological development have a negative impact to the follower's development growth. This is due to the formulation of the model in which a positive development gap (between the leader and the follower) causes the increase of the follower's growth rate, while a negative development gap, i.e. when the follower's level of development is higher that the leader's level of development, causes the decrease of the follower's growth rate. We have modified the model and obtained a more realistic result, in which the presence of technology transfer never been an obstacle for the follower to achieve the upper limit of the technological development. In the modified model we have assumed that technology transfer always has a non-negative impact on the indigenous ability of the follower to develop. Future work can be done by assuming that the presence of technology transfer might increase the original/indigenous upper limit of the technological development.

Another venue for future work can be described as the following. Regarding the original model of [19], a researcher in [15] pointed out that it takes the limit of the developments of the leader and the follower into account, but the absorbing capability of the follower remains the same throughout the process of the transfer. A model that takes the absorbing capability of the follower into account explicitly is developed in [15] and found an analytic solution of the model. However, the model fails to acknowledge the limit of the developments of the leader and the follower by assuming an unbounded increasing growth of the leader. Another contrast between Raz and Assa [19] and [15] is the fact that the former assumes that without any technology transfer from the leader, the follower could attain the maximum level of the technology development by solely use of its indigenous ability to develop, while the later assumes that there is no development for the follower without any technology transfer from the leader. Future work can be carried out by integrating or compromising those models to obtain a more general model (currently under investigation).

\section{ACKNOWLEDGEMENT}

The work reported in this paper is partially supported by the Directorate General of Higher Education, Indonesia, through Penelitian Hibah Bersaing to the first author and through Penelitian Hibah Kompetensi to the third author. 


\section{REFERENCES}

[1] Anggriani, N., Lesmana, E., Supriatna, A., Husniah, H., and Yudha, M., "Dynamic analysis of a two products inventory control", Jurnal Teknik Industri, Vol 17(1) (2015), 17-26 (in Indonesian).

[2] Bar-Zakay, S.N., "A Technology Transfer Model", Technological Forecasting and Social Change, 2 (1971), 321-337.

[3] Forrester, J., Forrester, Jay W. 1958. "Industrial Dynamics-A Major Breakthrough for Decision Makers." Harvard Business Review, Vol. 36, No. 4, pp. 37-66. Also appears in revised form as Chapter 2 in the author's Industrial Dynamics 1961 and Chapter 1, pp. 1-29, of Collected Papers 1975; also as Chapter 2, pp. 37-65 in Edward B. Roberts, ed., Managerial Applications of System Dynamics, 1978, all from Waltham, MA: Pegasus Communications, 1958

[4] Goc, M.L., "Development Techniques for International Technology Transfer", Book Review, Westport, CT: Quorum Books, pp 184, ISBN: 1-56720-493-7, Technological Forecasting and Social Change, Vol 70 (2002), 923-927.

[5] Haq, A.K.M.A., A Dynamic and Spatial Model for Measuring Technology Transfer Potentials, D.Eng. Dissertation, Asian Institute of Technology, 1979.

[6] Husniah, H., Pasaribu, U.S., Halim, A.H., and Iskandar, B.P., "Hybrid minimal repair and age replacement policy for two-dimensional warranted products", International Journal of Collaborative Enterprise, Vol 2(4) (2011), 284-301.

[7] Husniah, H., Pasaribu, U.S., Cakravastia, A., and Iskandar, B.P., "Two-dimensional maintenance contracts for a fleet of dump-trucks used in mining industry", Applied Mechanics and Materials, 660 (2014), 1026-1031.

[8] Husniah, H., Pasaribu, U.S., and Iskandar, B.P., "Service contracts management with availability improvement and cost reduction", ARPN journal of Engineering and Applied Sciences, Vol 10(1) (2015), 146-151.

[9] Iskandar, B.P., Husniah, H., and Pasaribu, U.S., "Maintenance service contracts for equipment sold with two-dimensional warranties", Quality Technology and Quantitative Management, Vol 11 (2014), 307-333.

[10] Jayaraman, V., A Quantitative Model for Measuring Technology Transfer at the Industrial Level An Application Towards Establishing Technological Cooperation, PhD. Thesis, School of Quantitative Methods and Business Operations, University of Western Sydney, Nepean, 1998.

[11] Kreng, V.B. and Wang, B.J., "An innovation diffusion of successive generations by system dynamics An empirical study of Nike Golf Company", Technological Forecasting and Social Change, Vol 80 (2013), 77-87.

[12] Kreyszig, E., Advanced Engineering Mathematics Sixth Edition, John Wiley \& Sons, New York, 1988.

[13] Kwasnicki, W., "Logistic growth of the global economy and competitiveness of nations", Technological Forecasting and Social Change, 80 (2013), 50-76.

[14] Lee A.H.I. Wang W.M., and Lin T.Y., "An Evaluation Framework for Technology Transfer of New Equipment in High Technology Industry", Technological Forecasting and Social Change, Vol 77 (2010), 135150.

[15] Liu, W.G., "A Quantitative technology transfer model and its application to aircraft engines", Technological Forecasting and Social Change 44 (1993), 179-186.

[16] Pachamuthu, S., An Extended Model for Measuring the Technology Transfer Potentials at the Industrial Level. Ph.D Thesis. Southern Cross University, Australia, 2011.

[17] Pasaribu, U.S., Husniah, H. and Iskandar, B.P., "A mathematical model for imperfect maintenance contract", International Journal of Applied Mathematics and Statistics, Vol 53(2) (2015), 20-35.

[18] Ramanathan, K., "The polytrophic components of manufacturing technology", Technological Forecasting and Social Change, 46 (1994), 221-258. 
[19] Raz, B. and Assa, I., "A model of "Coupled" Technology Transfer. A Logistic Curve Approach", Technological Forecasting and Social Change, 33 (1988), 251-265.

[20] Raz, B., Steinberg, G., and Ruina, A., "A Quantitative Model for Technology Transfer and Technological Catch-up The Case of Developing Countries", Technological Forecasting and Social Change, Vol 3 (1983), 251-265.

[21] Sharif, M.N., and Ramanathan, K., "Polynomial Innovation Diffusion models", Technological Forecasting and Social Change, Vol 21 (1982), 301-323.

[22] Souder, W.E., Nashar, A.S. and Padmanathan, V., "A guide to the best technology transfer practices", Journal of Technology Transfer, 15 (1990), 1-2.

[23] Sukchareonpong, P., A Quantitative Model Incorporating Time and a Dynamic Technological Gap for Determining Technology Transfer Potentials, D.Eng. Dissertation, Asian Institute of Technology, 1979.

[24] Tsai, B.H., "Predicting the diffusion of LCD TVs by incorporating price in the extended Gompertz model", Technological Forecasting and Social Change, Vol 80 (2013), 106-131.

[25] Verhults, F., Nonlinear Differential Equations and Dynamical Systems, Universitex, 1989.

[26] Vogel, P.H., "A Basis for Technological Forecasting", Technological Forecasting, 1 (1970), 313-323. 
H. Husniah, et al. 